Article

\title{
Experimental and Numerical Study of a Microcogeneration Stirling Unit under On-Off Cycling Operation
}

\author{
Gianluca Valenti ${ }^{1, *(\mathbb{D}}$, Aldo Bischi ${ }^{2}$, Stefano Campanari ${ }^{1}$, Paolo Silva ${ }^{1} \mathbb{D}$, Antonino Ravidà $^{1} \mathbb{D}$ \\ and Ennio Macchi ${ }^{1}$ (D)
}

1 Department of Energy, Politecnico di Milano University, Via Lambruschini 4/A, 20156 Milano, Italy; stefano.campanari@polimi.it (S.C.); paolo.silva@polimi.it (P.S.); antonino.ravida@polimi.it (A.R.); ennio.macchi@polimi.it (E.M.)

2 Center for Energy Science and Technology, Skolkovo Institute of Science and Technology, Bolshoy Boulevard 30, 121205 Moscow, Russia; a.bischi@skoltech.ru

* Correspondence: gianluca.valenti@polimi.it; Tel.: +39-02-2399-3845

Citation: Valenti, G.; Bischi, A.; Campanari, S.; Silva, P.; Ravidà, A.; Macchi, E. Experimental and Numerical Study of a Microcogeneration Stirling Unit under On-Off Cycling Operation. Energies 2021, 14, 801. https:// doi.org/10.3390/en14040801

Academic Editor: Dimitris Katsaprakakis

Received: 8 December 2020

Accepted: 25 January 2021

Published: 3 February 2021

Publisher's Note: MDPI stays neutral with regard to jurisdictional claims in published maps and institutional affiliations.

Copyright: (c) 2021 by the authors. Licensee MDPI, Basel, Switzerland. This article is an open access article distributed under the terms and conditions of the Creative Commons Attribution (CC BY) license (https:// creativecommons.org/licenses/by/ $4.0 /)$.

\begin{abstract}
Stirling units are a viable option for micro-cogeneration applications, but they operate often with multiple daily startups and shutdowns due to the variability of load profiles. This work focused on the experimental and numerical study of a small-size commercial Stirling unit when subjected to cycling operations. First, experimental data about energy flows and emissions were collected during on-off operations. Second, these data were utilized to tune an in-house code for the economic optimization of cogeneration plant scheduling. Lastly, the tuned code was applied to a case study of a residential flat in Northern Italy during a typical winter day to investigate the optimal scheduling of the Stirling unit equipped with a thermal storage tank of diverse sizes. Experimentally, the Stirling unit showed an integrated electric efficiency of $8.9 \%(8.0 \%)$ and thermal efficiency of $91.0 \%(82.2 \%)$, referred to as the fuel lower and, between parenthesis, higher heating value during the on-off cycling test, while emissions showed peaks in NOx and CO up to $100 \mathrm{ppm}$ but shorter than a minute. Numerically, predictions indicated that considering the on-off effects, the optimized operating strategy led to a great reduction of daily startups, with a number lower than 10 per day due to an optimal thermal storage size of $4 \mathrm{kWh}$. Ultimately, the primary energy saving was $12 \%$ and the daily operational cost was $2.9 € /$ day.
\end{abstract}

Keywords: micro-CHP; cogeneration; transient operation; mixed integer linear programming; optimal schedule

\section{Introduction}

Micro-cogeneration Stirling units are a viable option for small-scale residential and commercial applications because of their high total efficiencies, favorable ratios of thermalto-electric power with respect to the loads they must meet, low $\mathrm{CO}$ as well as NOx emissions, extended time between maintenances, and reduced vibrations during operation $[1,2]$. In contrast to the case of large industrial applications where both thermal and electric loads are relatively constant throughout the year, residential and commercial applications are characterized by large fluctuations of electricity, heating, and cooling loads, which are strictly related to climatic conditions and to the end-users' needs. On top of these load fluctuations, electricity tariffs feature typically daily and weekly variations, while the option of selling the electricity to the grid can be subjected to constraints and may turn economically unattractive. Within this framework, a number of studies indicate that the optimal scheduling from the economic perspective of micro-cogeneration units, optionally equipped with thermal storage, requires switching on and off the units several times during the day and the week [3-8]. However, some studies highlight the strong influence of transients during startups and shutdowns, demonstrating significant effects in terms 
of variation of electric as well as thermal efficiencies, pollutant emissions, and auxiliary consumption [9-12].

The goal of the present work was assessing the effects from energy, economic, and emission perspectives of the on-off cycling on a typical winter day operation of a Stirling unit by way of experimental and numerical activities. In the first stage of three, the work focused on the experimental steady-state and, in particular, on on-off cycling tests of a natural gas-fired small-size commercial Stirling unit. In the second one, the measurements were utilized to tune an in-house mixed integer linear programming (MILP) optimization model, which has been developed over the years for cogeneration plant scheduling, to account for the transient effects of startups and shutdowns on electric and thermal productions. Ultimately, in the third and last stage, the tuned model was employed to simulate the application of the Stirling unit, equipped with a thermal storage tank, to a case study, a flat in Northern Italy, that was characterized by variable electric and thermal loads over a winter day. Due to the importance of the tank size, a parametric analysis on its capacity was conducted. The second and third stages of this work considered the possibility of running only the main burner because it was a simple condition yet very representative of the transient effects.

Micro-cogeneration units based on Stirling engines have been widely analyzed, developed, and proposed at research, development, and commercial levels $[13,14]$. The commercial Stirling unit used in this work is model named WhisperGen, sixth generation, by the company EHE, previously by Whisper Tech, which is a double-acting alpha-type four-cylinder unit, using nitrogen as working fluid, adopting a premix natural-gas burner (while previous generations were powered by diesel fuel), converting the alternating to the rotating movement by wobble yoke mechanisms, and generating electricity in an on-grid configuration [15-20]. Nominally, the unit is capable of cogenerating $1 \mathrm{~kW}_{\mathrm{e}}$ of electricity, without possibility of regulating it, and about $8 \mathrm{~kW}_{\text {th }}$ of hot water, which could be increased in a single step up to about $12 \mathrm{~kW}$ by an auxiliary burner that operates in a non-cogenerative configuration. The unit is proved experimentally to achieve a net electric efficiency in the neighborhood of $11 \%$ and a thermal one exceeding $78 \%$ based upon the return water temperature.

The novelty of this work consisted in investigating both experimentally and numerically whether the optimal management of a micro-cogeneration unit shall consider or not the transient effect of the startup. Therefore, the analysis allowed us to define guidelines in terms of number of daily startups and tank capacity relative to the unit size, with a potential impact on research related to investigating and developing micro-cogeneration units, as well as on their successful deployment.

\section{Experimental Campaign}

This section covers the experimental campaign conducted on the micro-cogeneration Stirling unit, providing a description of the test rig along with the procedure, and illustrating after the results.

\subsection{Campaign Description}

The general experimental setup for testing the Stirling unit provided measurements that were taken at the boundary of the unit itself. Regarding the input gas flows, which are the natural gas from the national grid and the ambient air, the setup allowed us to acquire the temperature and the pressure of both. Additionally, the mass flow rate and the volume composition of the natural gas, the latter by a micro gas chromatograph, as well as the relative humidity of the ambient air, were collected. The ambient air temperature was controlled by way of a heating, ventilating, and air conditioning system: The set point was $25{ }^{\circ} \mathrm{C}$ in all tests. Regarding the output flue gas, the measures included: Temperature and emissions $\left(\mathrm{CO}, \mathrm{NO}, \mathrm{NO}_{2}, \mathrm{SO}_{2}\right.$, and $\left.\mathrm{O}_{2}\right)$ by an electrochemical analyzer. For the cogeneration water, temperatures, differential pressure, and mass flow rate were acquired. In particular, the inlet flow rate of the water was controlled through a variable-speed 
pump: The set point was always $0.194 \mathrm{~kg} / \mathrm{s}$, which was the nominal flow rate of the unit. At the same time, the inlet temperature was controlled by a water-tower cooling system: The set point was always $50^{\circ} \mathrm{C}$, which was a typical condition for micro-cogeneration applications as well as for the case study described in Section 4. Lastly, the remaining instruments comprised an electric power analyzer to measure the electric production, in terms of voltage, current, power factor, and, hence, power, and a load cell to weigh the condensate water from the flue gas. Figure 1 depicts the Stirling unit and the experimental setup, while Table 1 provides information on manufacturer, model, and measurement uncertainty of all instruments.

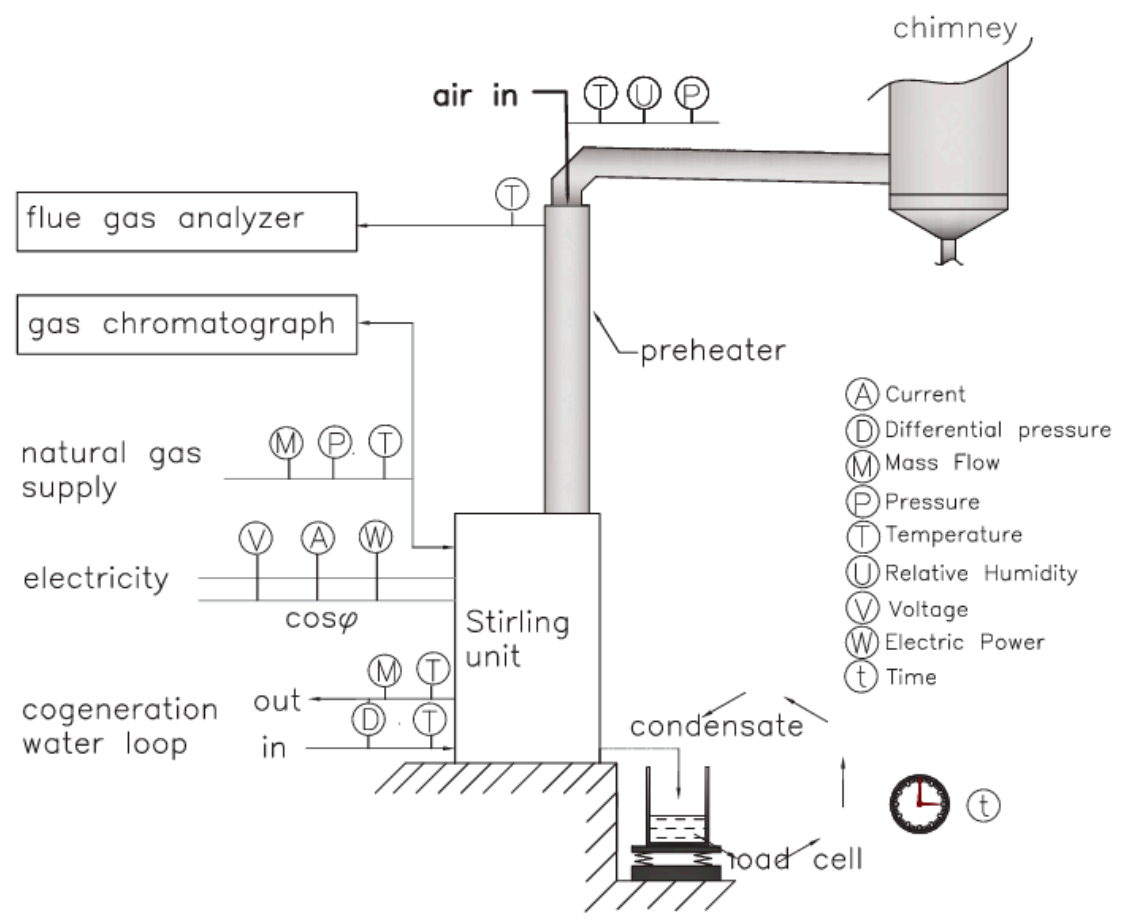

Figure 1. Schematic of the experimental setup showing the measurements acquired externally to the Stirling unit under testing of on-off cycling operation.

The experimental test of on-off cycle operations considered turning on and turning off the main burner so that the system would be brought to full electric power output and then stopped, repeating continuously the on-off cycling. The test began from a steady state nominal condition, which was verified observing the variation of the electric power generation that had to remain within a $\pm 10 \mathrm{~W}$ band for at least $10 \mathrm{~min}$, and of the cogeneration water inlet and outlet temperatures that had to remain within a $\pm 0.5^{\circ} \mathrm{C}$ band for the same time. From this steady-state condition, the burner was turned off for $10 \mathrm{~min}$ and, then, on for other $30 \mathrm{~min}$. Then, off and on again with the same timing, repeatedly. The test ended with the main burner running and the unit operating in a steady state.

During the steady states and the on-off cycling tests, all measures were acquired every $2 \mathrm{~s}$, except emissions from the electrochemical analyzer that were acquired every $30 \mathrm{~s}$, and compositions from the micro gas chromatographer every 3-5 min. Upon completion of a test, the recorded data were first filtered statistically, by highlighting possible outliers, and then were used to evaluate mass and energy integrals over the duration of the overall test. Lastly, integral values were employed to compute the experimental electric and thermal efficiencies. 
Table 1. Instrumentation list complete of manufacturer, model, and uncertainty (FS stands for full scale, RV for read value) employed in the experimental campaign.

\begin{tabular}{|c|c|c|c|}
\hline Property and Location & Manufacturer & Model & Uncertainty \\
\hline $\begin{array}{l}\text { Temperature water } \\
\text { inlet/outlet }\end{array}$ & Scandura & Pt100 4 wires & $1 / 3 \mathrm{DIN}$ \\
\hline Exhaust & Scandura & Pt100 4 wires & $1 / 3 \mathrm{DIN}$ \\
\hline Natural gas & TC Direct & Pt100 4 wires & $1 / 10 \mathrm{DIN}$ \\
\hline Mass flow rate water loop & Emerson & Micromotion Coriolis CMF025 & $\pm(0.1 \% \mathrm{RV})$ \\
\hline Natural gas & Bronkhorst & IN-FLOW 112-Al & $\pm(0.5 \% \mathrm{RV}+0.1 \% \mathrm{FS})$ \\
\hline Weight condensate water & Laumas & Load Cell-TLS420 & $\pm 0.25 \mathrm{~g}$ \\
\hline Ambient pressure & Vaisala & PTU300 & $\pm 0.15 \mathrm{hPa}$ \\
\hline Temperature & Vaisala & PTU300 & $\pm 0.10^{\circ} \mathrm{C}$ \\
\hline Relative humidity & Vaisala & PTU300 & $\pm 1.0 \%$ RH @40 ... 97\% RH \\
\hline Pressure natural gas & Bronkhorst & IN-PRESS P-502CI & $\pm(0.5 \%$ FS $)$ \\
\hline Water loop & Rosemount & $2088 \mathrm{~A}$ & $\pm(0.1 \%$ FS $) @ 0.1 \ldots 10$ bar \\
\hline $\begin{array}{l}\text { Differential pressure } \\
\text { water loop }\end{array}$ & Rosemount & $2051 \mathrm{CD}$ & $\pm(0.075 \%$ FS $) @ 0 \ldots 2.6$ bar \\
\hline Emissions & Testo & Testo 360 & $\begin{array}{c}\mathrm{O}_{2}: \pm(0.2 \% \text { pt RV }) \\
\mathrm{CO} / \mathrm{H}_{2}: \pm 50 \mathrm{ppm} \\
\mathrm{NO}, \mathrm{NO}_{2}, \mathrm{SO}_{2}: \pm 10 \mathrm{ppm}\end{array}$ \\
\hline Gas composition & Pollution & $\begin{array}{l}\text { VEGA-GasCromatograph } 3000 \\
3 \text { columns Cpsil, Molsieve, PPQ }\end{array}$ & $2 \%$ on each species (but methane $0.2 \%$ ) \\
\hline Electric power & Fluke & NORMA 4000 & $\pm 0.1 \% \mathrm{RV}$ \\
\hline
\end{tabular}

\subsection{Campaign Results and Discussion}

Figure 2 shows the unit operation as a function of time during the on-off cycling after a steady state in terms of natural gas flow rate [liter/min at normal conditions], electric power output $(\mathrm{W})$ of the temperatures of the cogeneration water at inlet and outlet, as well as the temperature of the exhaust $\left({ }^{\circ} \mathrm{C}\right.$ ), and emissions of $\mathrm{NOx}$ and $\mathrm{CO}$ referred to $6 \% \mathrm{O}_{2}$ volume dry conditions. In particular, Figure 2 shows negative values of the electric power upon shutting down the unit because power was consumed to slow down gradually the moving parts and to keep the fan on to air-wash the combustion chamber. Moreover, each startup yielded peaks in NOx and in $\mathrm{CO}$ emissions, which, however, remained below the maximum values of about 100 ppm for $\mathrm{CO}$ and 20 ppm for NOx and lasted for a very short time, less than $1 \mathrm{~min}$. These results confirmed the low environmental impact that is typical of Stirling units even in on-off cyclic operations.

Table 2 reports the averaged performances of the Stirling unit in steady-state conditions, taken as reference, and the integrated performances during the on-off cycling of the main burner. The steady-state performances were: $10.8 \%(9.7 \%)$ electric, $90.1 \%(81.4 \%)$ thermal, and $100.9 \%(91.1 \%)$ total efficiency with the main burner, all expressed with respect to the measured lower heating value and, between parenthesis, to the higher heating value of the fuel. These steady-state outcomes were in agreement with analogue measurements in the literature [15-18]. The on-off cycling results showed a significant decrease of the electric efficiency when integrated on the test period, and a modest increase in the thermal one. The on-off cycling featured an $8.9 \%$ (8.0\%) average electric efficiency, resulting in $1.9 \%$ pts $(1.7 \%$ pts $)$ decrease with respect to the steady-state condition, and featured a $91.0 \%$ $(82.2 \%)$ average thermal efficiency, resulting in a $0.9 \%$ pts $(0.8 \%$ pts) increase. Overall, the average total efficiency was $99.9 \%(90.2 \%)$, resulting in a $1.0 \%$ pts $(0.9 \%)$ decrease. These on-off cycling outcomes were in agreement with analogue measurements in the literature [19]. These experimental results suggest limiting the frequency of startups during real operation in order to maintain the electric efficiency close to the nominal value and to reduce pollutant emissions. 


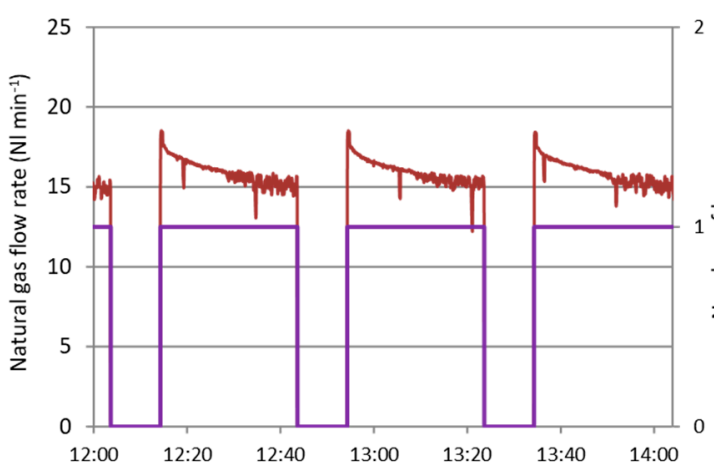

(a)

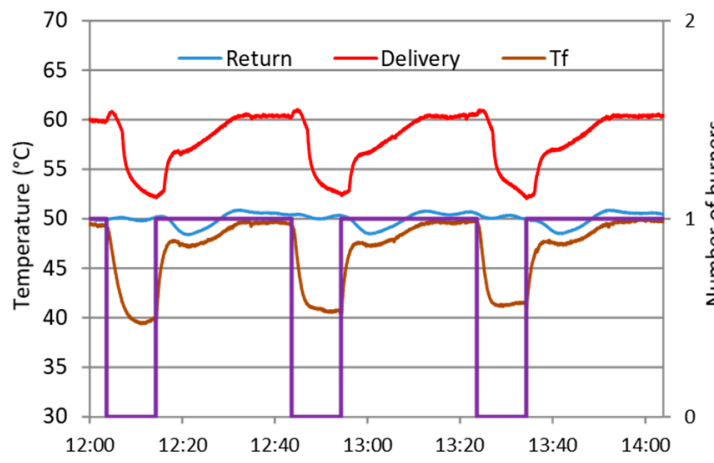

(c)

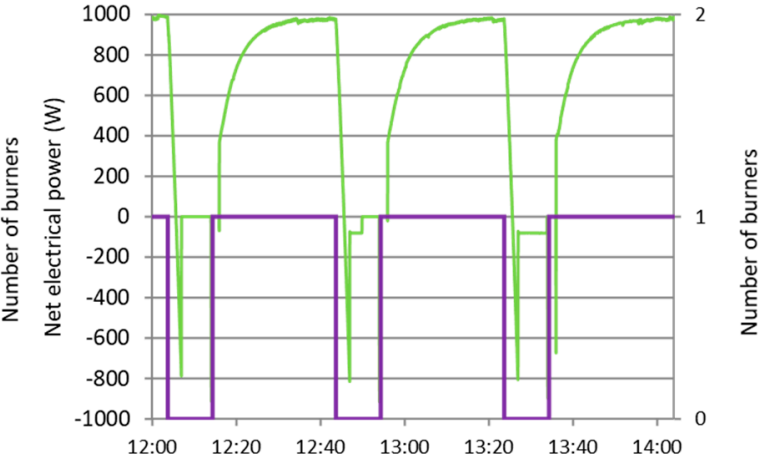

(b)

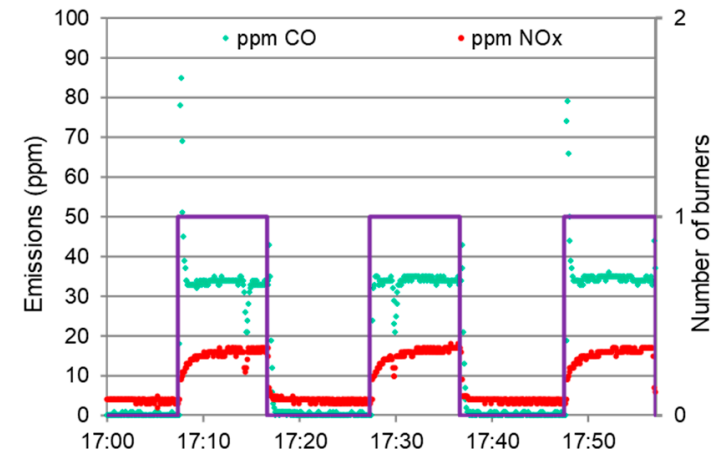

(d)

Figure 2. Experimental results of the test on the on-off cycling of the main burner (violet lines show the main burner): (a) Natural gas flow rate ( $\mathrm{Nl} / \mathrm{min})$; (b) net electric power $(\mathrm{W})$ (positive is produced, negative consumed); (c) temperatures $\left({ }^{\circ} \mathrm{C}\right)$ of water return (blue line), water delivery (red line), and exhaust (brown line); (d) emissions of $\mathrm{CO}$ and $\mathrm{NO}_{\mathrm{x}}$, referred to $6 \% \mathrm{O}_{2}$ volume dry conditions.

Table 2. Experimental results of the Stirling unit performances at steady state operation as well as integrated over the test duration under on-off cycling of the main burner. In the tests, the water inlet temperature is controlled at $50{ }^{\circ} \mathrm{C}$ and mass flow rate at $0.194 \mathrm{~kg} / \mathrm{s}$, which is the nominal value. LHV and HHV stand for lower/higher heating value.

\begin{tabular}{ccccccc}
\hline \multirow{2}{*}{ Operation Type } & \multicolumn{2}{c}{ Electric Efficiency } & \multicolumn{2}{c}{ Thermal Efficiency } & \multicolumn{2}{c}{ Total Efficiency } \\
\cline { 2 - 7 } & LHV Basis & HHV Basis & LHV Basis & HHV Basis & LHV Basis & HHV Basis \\
\hline Steady-state & $10.8 \%$ & $9.7 \%$ & $90.1 \%$ & $81.4 \%$ & $100.9 \%$ & $91.1 \%$ \\
On-off cycling & $8.9 \%$ & $8.0 \%$ & $91.0 \%$ & $82.2 \%$ & $99.9 \%$ & $90.2 \%$ \\
\hline
\end{tabular}

\section{Optimization Model}

This section covers the optimization model employed in the numerical analysis, providing the problem statement, the description of the approach, and the procedure for tuning it.

\subsection{Problem Statement}

The optimization model employed in the second stage of the present work aimed at computing the optimal short-term scheduling of the micro-cogeneration Stirling unit, quantifying the daily operational costs and, accordingly, the primary energy consumptions, in order to identify the best storage size. The optimization problem could be stated as follows.

Given:

- One micro-cogeneration unit with fixed size, performance curve, startup and shutdown times; 
- $\quad$ Storage tank with fixed capacity and constant loss rate;

- Time-dependent demands of thermal and electric energy;

- Time-dependent price of electricity;

- Determination for each time step, $t$, of a time period, $T$ :

- The unit status, switched on or off;

- The value of the operative variable;

- The storage tank level,

the operating cost would be minimized while satisfying the demands.

\subsection{Model Description}

As per the problem statement, the model computes the optimized scheduling of the micro-cogeneration unit. In general, optimal scheduling requires determining which unit to switch on or off and at which load in order to meet both the electric and the thermal loads of the end-user. In general, the scheduling sets a number of challenges because electric and thermal loads are generally non-linear functions of the loads and because different combination of units can be operated to satisfy them. On top of this, the optional presence of a thermal storage tank and of constraints on startups links strictly the optimal scheduling of a certain simulation time step to the whole period taken into consideration. In other words, the problem is challenging because each simulation time step cannot be studied separately and the whole period must be optimized at once.

The optimized scheduling of a general cogeneration plant is a typical example of mixed integer non-linear problem (MINLP), as the possibility of switching on and off the units and deciding the most economical or efficient option require the adoption of integer variables, while the unit characteristic curves are usually non-linear. However, the state-ofthe-art MINLP solvers require high computational times for relatively small numbers of variables, and they do not necessarily find the global optimum, especially if the problem is non-convex. On the contrary, mixed integer linear programming (MILP) algorithms are capable of finding the global optimum for problems with thousands of variables and constraints within reasonable computational times due to the strong convergence guaranteed by the problem linearity and to the continuous improvement of numerical solvers. For these reasons, the state of the art approach implies linearizing a challenging MINLP problem into a more manageable MILP problem by means of diverse techniques, approximating as an example all units' characteristic curves as well as their constraints via piecewise linearization [21]. The model is written in the AMPL algebraic modeling language and the resulting MILP is solved with IBM ILOG CPLEX Optimizer. The code, described in detail in a previous work with the full set of equation [22], was validated against heuristic methods based on engineering best practices and tested with many units described by non-linear and even non-convex characteristic curves [23-25].

Compared to the general capability of the optimization model, the case study analyzed here was relatively simple because the electric and thermal efficiencies were only a function of the time lapse since the last startup and shutdown and they both turned constant sufficiently away from the last event because the Stirling unit could not modulate its outputs. This non-linearity during the transients could be treated accounting simply for an extra fuel consumption, a deficient electric production, and a deficient thermal production at the startup, as well as an extra thermal production at the shutdown. Considering that for each time step, $t$, an integer variable defined whether the engine status was on or off, an extra integer auxiliary variable was considered with a set of constraints forcing it to be equal to 1 at time $t$ if, and only if, the unit was off at time $t-1$. In this way, it was possible to identify the engine startups, so that its performance could be adjusted accordingly. The last time step of the optimized period the unit was forced to go back to the same conditions as the starting one.

Looking at the heat storage, this was modeled within the thermal balance constraint, because for each time step $t$ the difference between the current amount of stored energy and that one at the time $t+1$ told how much energy had been charged (in case of positive 
value) or discharged (negative). Furthermore, the stored energy should have always been above zero and below the maximum capacity. Constant thermal losses were inserted as a factor to multiply the amount of stored energy each time step $t$. The storage tank was assumed to be full at the beginning of the optimization period $T$. Leaving the starting level of the storage as a variable to optimize would determine a different starting value at each different instance making unfair the comparison. Furthermore, at the end of the last time step $t$ of the optimized period $T$, the storage level was obliged to charge or discharge energy so that the next day would start with the same level as the optimized one, full in this case.

\subsection{Model Tuning}

The experimental results were utilized to quantify the penalization related to the on-off cycling operation. Numerically, as already mentioned, the startup penalization included an extra fuel consumption, a deficient electric production, as well as a deficient thermal production during the transient period from the startup until the steady-state condition. Physically, this penalization was related to the energy required to warm the unit up to steady-state temperature. In contrast, at the shutdown, both fuel consumption and electric production were null, whereas there was an extra thermal production, which was related to the energy retrieved from cooling the unit. Numerically, the shutdown extra thermal production was discounted from the startup deficient thermal production. In other words, the penalization on thermal production was attributed only at the startup, but it included the net effect of a startup and the following shutdown, while the penalizations on fuel consumption and electric production occurred and were attributed only at the startup.

The extra and deficient terms were computed integrating the measured data of a natural gas flow rate, electric power output, as well as flow rate and temperature at the inlet and at the outlet of the cogeneration water. The startup integrals were executed over a 30 min period, which was the time span required to achieve steady-state conditions, while the shutdown ones were over a 10 min period, which was the time span required by the delivery temperature to cool down to $50{ }^{\circ} \mathrm{C}$; this value was indeed the return temperature setpoint during operation. The net effect of startup and shutdown thermal production led to a negative value, which meant to a net deficient thermal production. Lastly, the extra fuel consumption, the deficient electric production, and the net deficient thermal production at the startup were applied to the first simulation time step following the startup itself.

\section{Case Study}

This section covers the case study considered in this work, providing first a description of the case along with the electric and heating loads, and illustrating after the results.

\subsection{Case Description}

The case study was a residential flat in Northern Italy on a winter day [26]. The thermal load included the domestic hot water and the heating water. The heating system was assumed to be based on radiators, which imposed a temperature of the delivery water from the Stirling unit at $60{ }^{\circ} \mathrm{C}$ and of return water at $50{ }^{\circ} \mathrm{C}$. These temperatures were in strict agreement with the experimental campaign described in Section 2 . The time step for all the simulations was taken to be $10 \mathrm{~min}$. Hence, Figure 3 illustrates the electric and thermal loads as a function of the chosen simulation time step.

The energy flows of the Stirling unit equipped with a thermal storage and applied to the case study are represented in Figure 4. The thermal storage comprised conceptually both the storage capacity in the heating system, consisting of radiators as well as pipes, and the actual storage in a dedicated tank. The storage capacity of the heating system was estimated to be $1 \mathrm{kWh}$, while the capacity of the tank was varied from 0 to $9 \mathrm{kWh}$. Globally, the thermal storage capacity varied from 1 to $10 \mathrm{kWh}$ in this work. Moreover, the heat loss of the thermal storage tank during each hour was estimated to be $0.2 \%$ of the stored energy, assuming that the unit and the tank were located inside a ventilated technical room. This 
heat loss did not provide heat to the end-user. In addition, the thermal storage tank was assumed to be completely full at the beginning and at the end of the day.

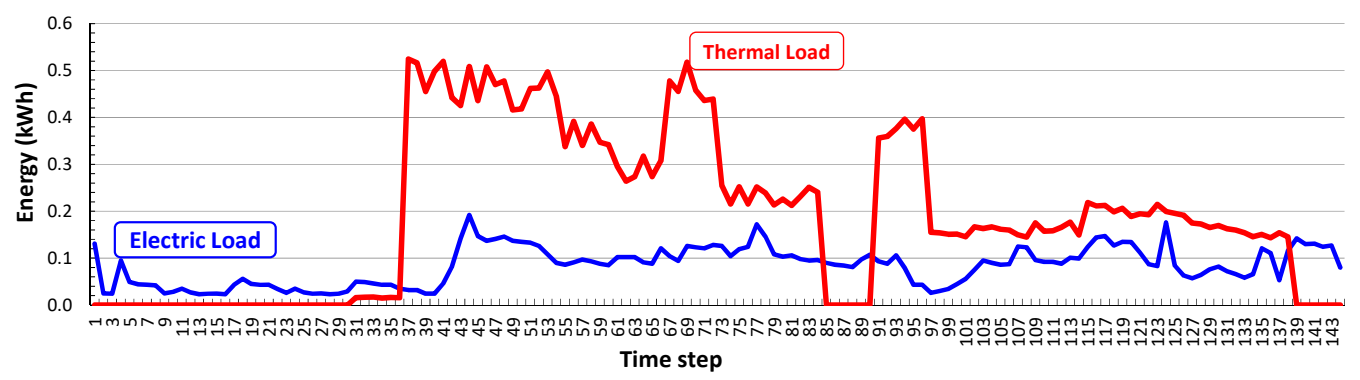

Figure 3. Electric and thermal loads for a residential flat in Northern Italy defined with a time step of 10 min over a typical winter day.

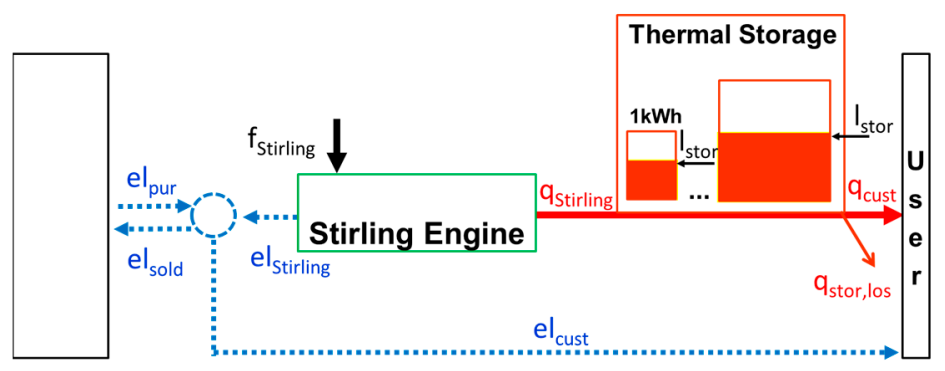

Figure 4. Schematic representation of the system energy fluxes considered in the case study; thermal storage may range from 1 to $10 \mathrm{kWh}$, out of which $1 \mathrm{kWh}$ is due to the heating system and 0 to $9 \mathrm{kWh}$ the thermal storage tank. From left to right, the short "el" stands for electricity, "pur" for purchased, "f" for fuel, "cust" for customer, "stor" for storage.

Noticeably, the daily periodicity was taken in strict agreement with the standard DIN 4709 , which describes a protocol for testing micro-cogeneration units under a simplified daily profile [27]. Consequently, a dedicated constraint in the model imposed that at the beginning of the twenty-fifth hour, which is the first hour of the following day, the thermal storage had to be full as at the beginning of the first hour. Lastly, electricity could be sold or purchased from the grid if economically favorable.

\subsection{Case Results and Discussion}

The case study was employed for a number of simulations. Each simulation was characterized by the value of the thermal storage capacity, ranging from 0 to $9 \mathrm{kWh}$. Moreover, each simulation was launched excluding as well as including the transient penalization in order to evaluate the effect of the penalization itself. Table 3 reports the common energy and cost assumptions for all simulations. In particular, the values of penalization of each startup were those computed from the experimental campaign. Each startup yielded a transient lasting about $30 \mathrm{~min}$, increased the fuel consumption by $0.063 \mathrm{kWh} \mathrm{LHV}_{\mathrm{LH}}$, and reduced the electric production by $0.079 \mathrm{kWh}_{\mathrm{e}}$. Moreover, each startup combined with a subsequent shutdown reduced the thermal production by $0.163 \mathrm{kWh}_{\mathrm{th}}$ as a net effect.

All simulations were executed on an Intel Xeon with E5-2690V2 @3.0GHz CPUs and 32 GB RAM, with each having one dedicated core. The number of variables was 2880, out of which 2737 were continuous and 143 binary, while the constraints were 3458 . The reduced number of integer variables was related only to the decision regarding whether the units should be switched on or off in each of the 144 time steps in a day. As a convergence criterion, the relative MIL gap was set to $0.1 \%$ with a time limit of $3000 \mathrm{~s}$

Figure 5 shows the computational results in an aggregated form for the thermal storage ranging from 1 to $10 \mathrm{kWh}$. The optimal number of startups decreased dramatically with an 
increasing capacity of the storage, for both the cases without (a) and with (b) penalization, until a certain size where it tended to level out. This level was around 10 startups in the first case and around 5 in the second. In the case with penalization, the optimal number of startups was much smaller, roughly $40 \%$ on average, with respect to the case without penalization at same thermal storage capacity, indicating that the loss of overall efficiency, and especially electric efficiency, during the transients had a major influence. Likewise, the primary energy savings, which were of course higher in the case study (a) without penalization, improved substantially at increasing capacity of the thermal storage tank in case (b) with penalization up to achieving a plateau. Furthermore, in the latter case, the objective function representing the daily operational costs, which includes as said fuel purchase as well as electricity purchase and sale, was decreasing with increasing size of the tank due to a smarter management of the thermal energy. Finally, the thermal storage losses became increasingly larger in absolute terms, making it not profitable to oversize the storage. The optimal number of startups at the thermal storage capacity of $4 \mathrm{kWh}$ was 11 and 6, respectively, without and with penalization, and at the capacity of $10 \mathrm{kWh}$ this was 8 and 3, respectively. Primary energy savings were approximately $15 \%$ without penalization and $10 \%$ with penalization, while daily costs were about 2.8 and $2.9 € /$ day in the two cases.

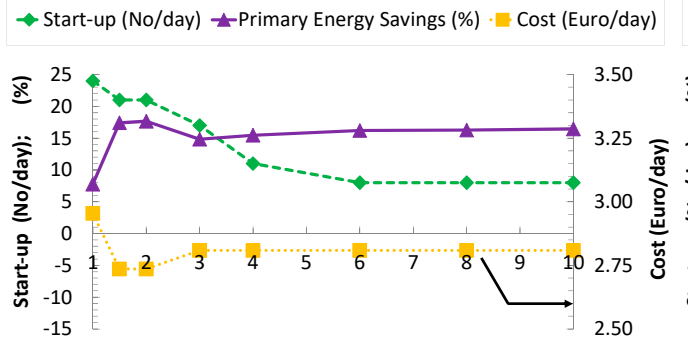

(a)

Heat Storage Size (kWh)

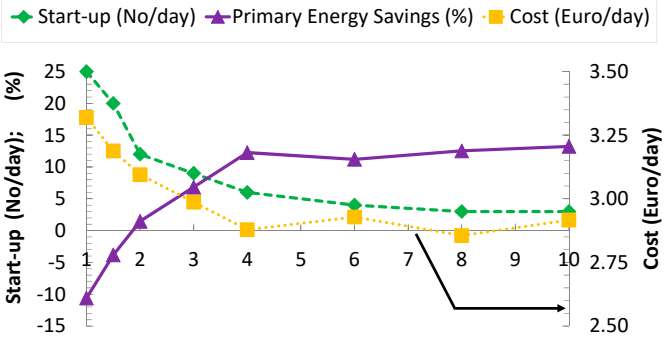

(b)

Heat Storage Size (kWh)

Figure 5. Computational results of the optimal scheduling of a small-size Stirling unit for the case study of a residential flat in Northern Italy during a typical winter day: (a) Without and (b) with startup and shutdown penalization. The number of startups and the primary energy savings are on the left-hand side axis and the objective function, which is the daily costs of operation, on right one.

Ultimately, Figures 6 and 7 depict the daily scheduling for the case of a 4 and $10 \mathrm{kWh}$ capacity of the thermal storage, respectively. As before, each figure reports the case without penalization ( $a$ and $b$ ) and with penalization (c and d). In both cases, the optimal strategy in correspondence of the first hours of the day, when the electric loads were small and thermal loads were not present, consisted of purchasing electricity from the grid, while the thermal storage tank was losing energy due to thermal losses. The first thermal load was covered via the thermal storage and the unit was started up only when the storage was close to being empty in order to meet the thermal load and, concurrently, to fill the tank. This was due to the relatively low electric efficiency of the Stirling unit that made more convenient purchasing electricity than generating it when there was not a simultaneous thermal load. In the case penalization was accounted for, electric (c) and thermal (d) energy histograms corresponding to a startup were smaller than the other case, consistently with the penalization reported in Table 3. As a consequence, the unit operated continuously, once switched on, for a larger number of time steps. The limiting factor was usually the thermal storage level: The unit was switched off when the thermal storage tank became full and switched on when empty. The thermal storage management respected the constraint to reach at the first time step of the twenty-fifth hour the same level set at the beginning of first hour, as explained previously. 

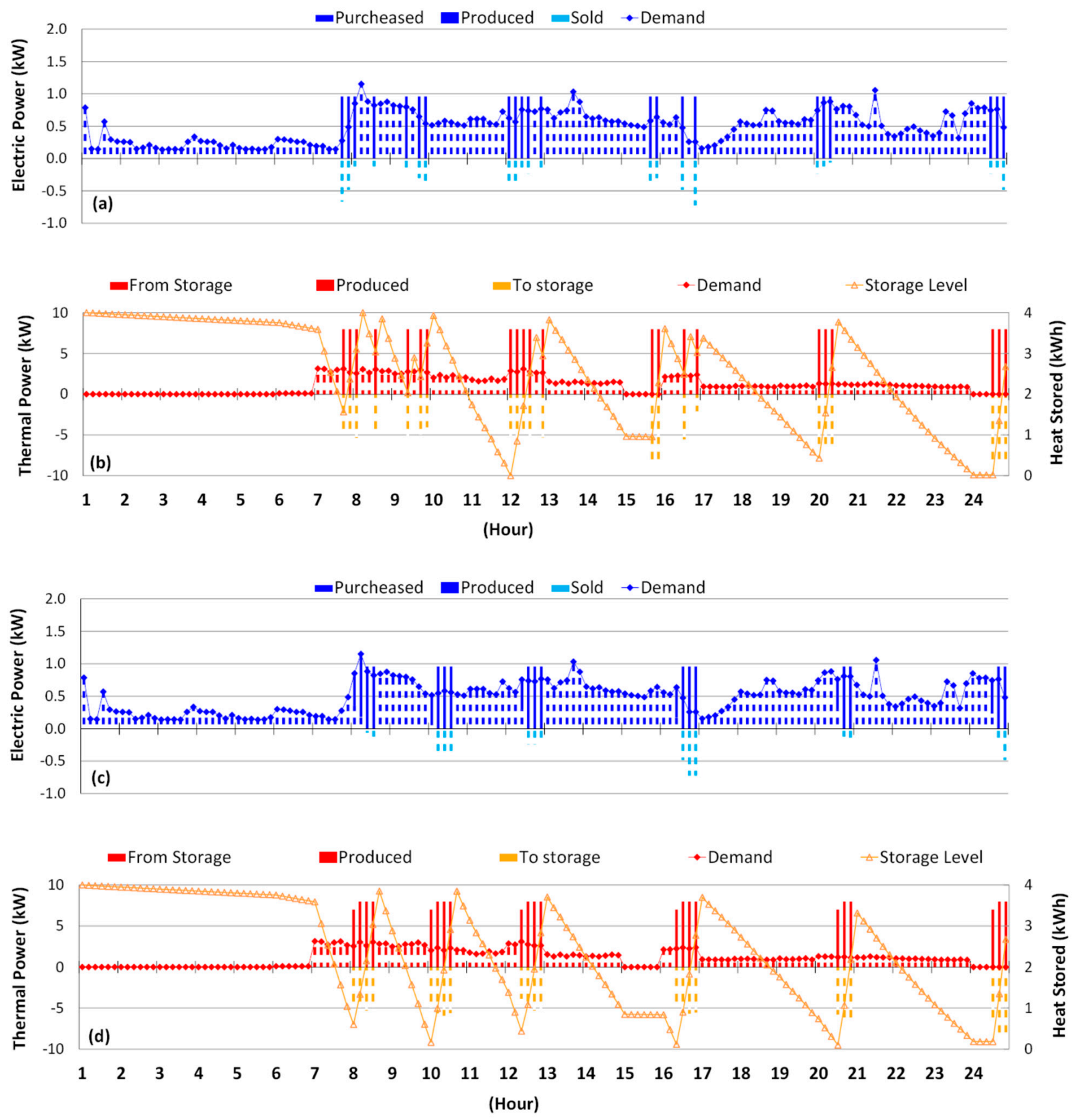

Figure 6. Computational results for a $4 \mathrm{kWh}$ thermal storage capacity (out of which $1 \mathrm{kWh}$ was due to the heating system and $3 \mathrm{kWh}$ to the thermal storage tank): (a) Electric and (b) thermal scheduling without startup and shutdown penalization; (c) electric and (d) thermal scheduling with startup and shutdown penalization. 

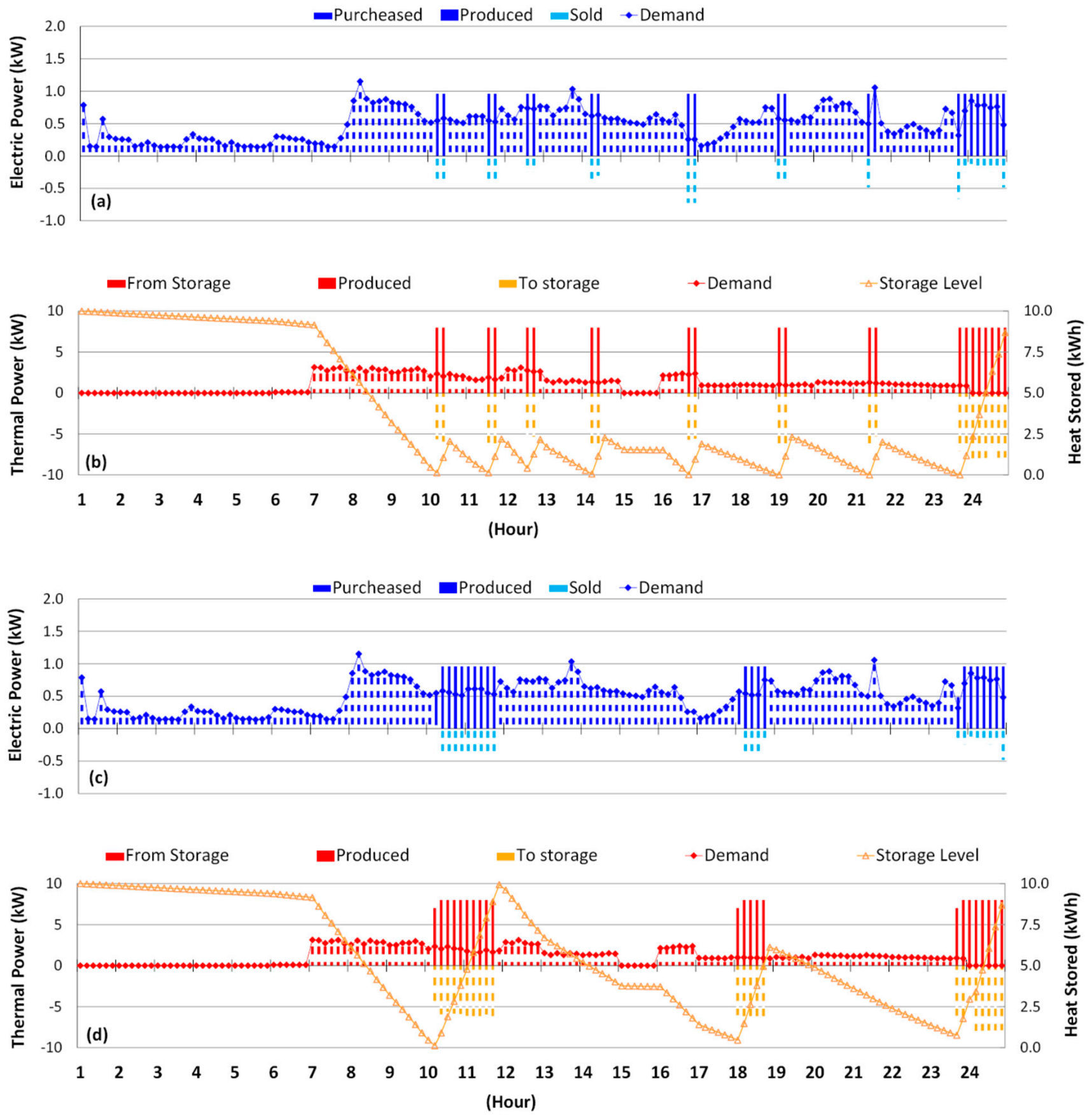

Figure 7. Computational results for a $10 \mathrm{kWh}$ thermal storage (out of which $1 \mathrm{kWh}$ was due to the heating system and 9 kWh to the thermal storage tank): (a) Electric and (b) thermal scheduling without startup and shutdown penalization; (c) electric and (d) thermal scheduling with startup and shutdown penalization.

It is possible to observe that the inclusion of startup and shutdown losses in the simulation was essential to allow a correct sizing of the thermal storage. The adoption of about $4 \mathrm{kWh}$ storage indeed allowed us to maximize the energy saving, reduce the operating costs and the number of stat-up per day. This also entailed a reduction in pollutant emissions, which showed peaks at each startup (Figure 2). 
Table 3. Energy and cost assumptions adopted in the simulations.

\begin{tabular}{ccc}
\hline Parameter & Unit & Value \\
\hline Thermal storage tank & & \\
Thermal loss (with respect to stored energy) & \%pt/time step & 0.2 \\
$\begin{array}{c}\text { Starting level (begin of day, first hour) } \\
\text { Ending level (end of day, twenty-fifth hour) }\end{array}$ & & Full \\
\hline Penalization for each startup & & Full \\
Fuel consumption (LHV) & & 0.063 \\
/Electric production & $\mathrm{kWh}_{\mathrm{LHV}}$ & -0.079 \\
Net thermal production & $\mathrm{kWh}_{\mathrm{el}}$ & -0.163 \\
\hline Fuel cost (LHV) & $\mathrm{kWh}_{\mathrm{th}}$ & 0.06 \\
\hline Electricity prices & $€ / \mathrm{kWh}_{\mathrm{th}}$ & \\
Purchase & $€ / \mathrm{kWh}_{\mathrm{el}}$ & 0.20 \\
Sale & & 0.10
\end{tabular}

* The net thermal production combines both the negative effect of a startup and the positive effect of the following shutdown on the thermal production.

\section{Overall Discussion}

The experimental campaign covered both the steady-state and the on-off cycling of the micro-cogeneration Stirling unit considered in this study. As seen, the experimental outcomes were in strict agreement with the literature and indicated that every turning on from an off condition lasting more than $10 \mathrm{~min}$ had an appreciable effect on the electric and the overall efficiency, suggesting the importance of limiting where possible the daily startups to reduce this penalization. In its turn, the optimization of the case study indicated that the on-off cycling penalization had to be considered in the simulations. Moreover, it provided a numerical indication on the optimal number of daily startups: Around 6 adopting a thermal storage equivalent to half-hour of operation at the nominal thermal power output, that is $4 \mathrm{kWh}$ here, and around 3 adopting a one-and-a-quarter hour equivalent storage, $10 \mathrm{kWh}$.

\section{Conclusions}

The present work analyzed the energy and cost penalties due to the on-off cycling operations of a Stirling unit by way of experimental and numerical activities. In particular, the case study of a small-sized commercial Stirling unit equipped with a thermal storage tank and applied to a Northern Italian flat during a typical winter day was investigated in detail. The work conclusions are as follows.

- Startup and shutdown cycles have a strong effect on the electric and thermal efficiencies; measured electric efficiencies may decrease by almost $2 \%$ points, while thermal efficiency decreases by less than $1 \%$ point. During startup, emissions showed peaks in NOx and $\mathrm{CO}$ up to $100 \mathrm{ppm}$ even if shorter than one minute.

- A 10-min simulation time step is a good option for the optimization of the scheduling, while taking into account the transient effects due to startups and shutdowns.

- The greater the size of the thermal storage tank, the smaller the number of startups with an asymptotic behavior due to the thermal losses of the tank. Similarly, the daily cost of operations tended to decrease with an increasing size of the tank due to a smarter management of the thermal energy. The primary energy saving was also positively affected by larger tanks.

- The positive effect of the thermal storage tank was even stronger when considering the startup and shutdown penalization in the calculation. Moreover, the inclusion of startup and shutdown losses in the simulation was essential to allow a correct evaluation of the thermal storage sizing.

- The optimal number of startups when considering the penalization had to be lower than 10 per day, while the primary energy saving was $12 \%$ and the daily operational 
cost slightly less than $2.9 € /$ day. The optimal size of the thermal storage was $4 \mathrm{kWh}$, equivalent to half-hour of steady-state operation.

Author Contributions: Conceptualization, S.C., G.V., and P.S.; methodology, G.V., P.S., and S.C.; software, A.B.; validation, S.C., G.V., A.B., and E.M.; investigation, A.B. and A.R.; data curation, A.B. and A.R.; writing—original draft preparation, G.V., S.C., and A.B.; writing—review and editing, E.M. and P.S.; supervision, E.M.; project administration, P.S. All authors have read and agreed to the published version of the manuscript.

Funding: This research was funded by Regione Lombardia through the Microgen project.

Institutional Review Board Statement: Not applicable.

Informed Consent Statement: Not applicable.

Data Availability Statement: Data is contained within the article.

Acknowledgments: The authors acknowledge gratefully the former students Andrea Cacace and Emanuele Zattoni who accomplished their graduate thesis working mainly on the Stirling unit tests.

Conflicts of Interest: The authors declare no conflict of interest.

$\begin{array}{ll}\text { Nomenclature } \\ \text { CHP } & \text { Combined heat and power } \\ \text { FS } & \text { Full scale } \\ \text { LHV } & \text { Lower heating value } \\ \text { MILP } & \text { Mixed integer linear programming } \\ \text { MINLP } & \text { Mixed integer non-linear problem } \\ \text { ppm } & \text { Parts per million } \\ \text { RV } & \text { Read value } \\ t & \text { Optimization time step } \\ T & \text { Optimization time period }\end{array}$

\section{References}

1. Allan, G.; Eromenko, I.; Gilmartin, M.; Kockar, I.; McGregor, P. The economics of distributed energy generation: A literature review. Renew. Sustain. Energy Rev. 2015, 42, 543-556. [CrossRef]

2. Uchman, W.; Kotowicz, J.; Remiorz, L. An experimental data-driven model of a micro-cogeneration installation for time-domain simulation and system analysis. Energies 2020, 13, 2759. [CrossRef]

3. Salgado, F.; Pedrero, P. Short-term operation planning on cogeneration systems: A survey. Electr. Power Syst. Res. 2008, 78, 835-848. [CrossRef]

4. Campanari, S.; Manzolini, G.; Silva, P. A Multi-Step Optimization Approach to Distributed Cogeneration Systems with Heat Storage. In Proceedings of the ASME Turbo Expo 2008: Power for Land, Sea and Air, Berlin, Germany, 9-13 June 2008; pp. 295-304.

5. Lu, Y.; Wang, S.; Sun, Y.; Yan, C. Optimal scheduling of buildings with energy generation and thermal energy storage under dynamic electricity pricing using mixed-integer nonlinear programming. Appl. Energy 2015, 147, 49-58. [CrossRef]

6. González-Pino, I.; Pérez-Iribarren, E.; Celador, A.C.; Las-Heras-Casas, J.; Sala, J. Influence of the regulation framework on the feasibility of a Stirling engine-based residential micro-CHP installation. Energy 2015, 84, 575-588. [CrossRef]

7. Wakui, T.; Kawayoshi, H.; Yokoyama, R.; Aki, H. Operation management of residential energy-supplying networks based on optimization approaches. Appl. Energy 2016, 183, 340-357. [CrossRef]

8. Manservigi, L.; Cattozzo, M.; Spina, P.R.; Venturini, M.; Bahlawan, H. Optimal management of the energy flows of interconnected residential users. Energies 2020, 13, 1507. [CrossRef]

9. Rosato, A.; Sibilio, S. Energy performance of a micro-cogeneration device during transient and steady-state operation: Experiments and simulations. Appl. Therm. Eng. 2013, 52, 478-491. [CrossRef]

10. Thiers, S.; Aoun, B.; Peuportier, B. Experimental characterization, modeling and simulation of a wood pellet micro-combined heat and power unit used as a heat source for a residential building. Energy Build. 2010, 42, 896-903. [CrossRef]

11. Valenti, G.; Campanari, S.; Silva, P.; Ravida, A.; Macchi, E.; Bischi, A. On-off cyclic testing of a micro-cogeneration stirling unit. Energy Procedia 2015, 75, 1197-1201. [CrossRef]

12. Wang, K.; Dubey, S.; Choo, F.H.; Duan, F. A transient one-dimensional numerical model for kinetic Stirling engine. Appl. Energy 2016, 183, 775-790. [CrossRef] 
13. Ahmed, F.; Huang, H.; Ahmed, S.; Wang, X. A comprehensive review on modeling and performance optimization of Stirling engine. Int. J. Energy Res. 2020, 44, 6098-6127. [CrossRef]

14. Wang, K.; Sanders, S.R.; Dubey, S.; Choo, F.H.; Duan, F. Stirling cycle engines for recovering low and moderate temperature heat: A review. Renew. Sustain. Energy Rev. 2016, 62, 89-108. [CrossRef]

15. D'Accadia, M.D.; Sasso, M.; Sibilio, S.; Vanoli, L. Micro-combined heat and power in residential and light commercial applications. Appl. Therm. Eng. 2003, 23, 1247-1259. [CrossRef]

16. Aliabadi, A.A.; Thomson, M.J.; Wallace, J.S.; Tzanetakis, T.; Lamont, W.; Di Carlo, J. Efficiency and emissions measurement of a stirling-engine-based residential microcogeneration system run on diesel and biodiesel. Energy Fuels 2009, 23, 1032-1039. [CrossRef]

17. Farra, N.; Tzanetakis, T.; Thomson, M.J. Experimental determination of the efficiency and emissions of a residential microcogeneration system based on a stirling engine and fueled by diesel and ethanol. Energy Fuels 2012, 26, 889-900. [CrossRef]

18. Ulloa, C.; Míguez, J.L.; Porteiro, J.; Eguia, P.; Cacabelos, A. Development of a transient model of a stirling-based chp system. Energies 2013, 6, 3115-3133. [CrossRef]

19. Thomas, B. Experimental determination of efficiency factors for different Micro-CHP units according to the standard DIN 4709. Appl. Therm. Eng. 2014, 71, 721-728. [CrossRef]

20. Valenti, G.; Silva, P.; Fergnani, N.; Campanari, S.; Ravida, A.; Di Marcoberardino, G.; Macchi, E. Experimental and numerical study of a micro-cogeneration Stirling unit under diverse conditions of the working fluid. Appl. Energy 2015, 160, 920-929. [CrossRef]

21. D'Ambrosio, C.; Lodi, A.; Martello, S. Piecewise linear approximation of functions of two variables in MILP models. Oper. Res. Lett. 2010, 38, 39-46. [CrossRef]

22. Bischi, A.; Taccari, L.; Martelli, E.; Amaldi, E.; Manzolini, G.; Silva, P.; Campanari, S.; Macchi, E. A detailed MILP optimization model for combined cooling, heat and power system operation planning. Energy 2014, 74, 12-26. [CrossRef]

23. Bischi, A.; Pérez-Iribarren, E.; Campanari, S.; Manzolini, G.; Martelli, E.; Silva, P.; Macchi, E.; Sala-Lizarraga, J.M.P. Cogeneration systems optimization: Comparison of multi-step and mixed integer linear programming approaches. Int. J. Green Energy 2016, 13, 781-792. [CrossRef]

24. Bischi, A.; Campanari, S.; Castiglioni, A.; Manzolini, G.; Martelli, E.; Silva, P.; Macchi, E. Tri-Generation Systems Optimization: Comparison of Heuristic and Mixed Integer Linear Programming Approaches. In Turbo Expo: Power for Land, Sea, and Air; American Society of Mechanical Engineers: New York, NY, USA, 2014.

25. Taccari, L.; Amaldi, E.; Martelli, E.; Bischi, A. Short-Term planning of cogeneration power plants: A comparison between MINLP and piecewise-linear MILP formulations. Comput. Aided Chem. Eng. 2015, 37, 2429-2434. [CrossRef]

26. Macchi, E.; Campanari, S.; Silva, P. La Microcogenerazione a Gas Naturale; Polipress: Milano, Italy, 2005.

27. Deutsches Institut für Normung. DIN 4709. Determination of the Standard Efficiency Factor for a Micro-Chp-Appliance of Nominal Heat Input Not Exceeding 70 kW; Deutsches Institut für Normung: Belin, Germany, 2011. 